of transformer which has been employed at the Thomson-Houston works. 'The core, $L$, is formed of a
bundle of fine iron wires, and around it is wound the primary coil, $P$, the terminals of which, AA, are con100 alternations per second. The length of the wire core is 12 in. and its diameter $11 / 4$ in. The secondary coil, S S, is composed of 64 No. 10 (Brown and Sharpe's gauge) copper wires, wound in parallel eight times to copper plates on which are mounted clamps, $C \mathrm{C}$ for the reception of the two rods, $R \mathbf{R}$, which are to be stantly pressed toward the other by a spring, so that resistance of be united are kept in 0.00015 ohm. The amount of energy given off by it can be varied by moving the core, $\mathrm{L} \mathrm{L}$, in and out of the primary coil.
Fig. 2 illustrates another construction of transformer. The primary coil, $P$, is a ring 12 in. in diameter, $2 \frac{1}{2}$ in. wide, and $3 / 4$ in. thick, of many turns of insulated copper wire lts ends, A A, are connected to the terminals
of the alternating dynamo. The secondary coil is a single heavy bar of copper, bent to make one turn out-
side the primary coil, and is represented by the heavy slack the primary coil, and is represented by the heavy parallel, and connected to massive clamps, M M. The drawn together by the adjustable spring, D. The primary and secondary coils are wound with an endless coil of iron wire, II. This does not touch the 0.0003 ing free. The resistance of the secondary coil is current it gives an electromotive force of 2 volts ; less, however, is used in most cases. In the primary circuit
there is used a current of 20 amperes and 600 volts, 25 horse power at 1,800 revolutions $500 \mathrm{lb}$., and absorbing horse power at 1,800 revolutions.

During the lecture mild steel rods, $1 / 2$ in. in diameter, were placed end to end in the clamps of the machine
(Fig. 2), and were welded before the audience. Copper

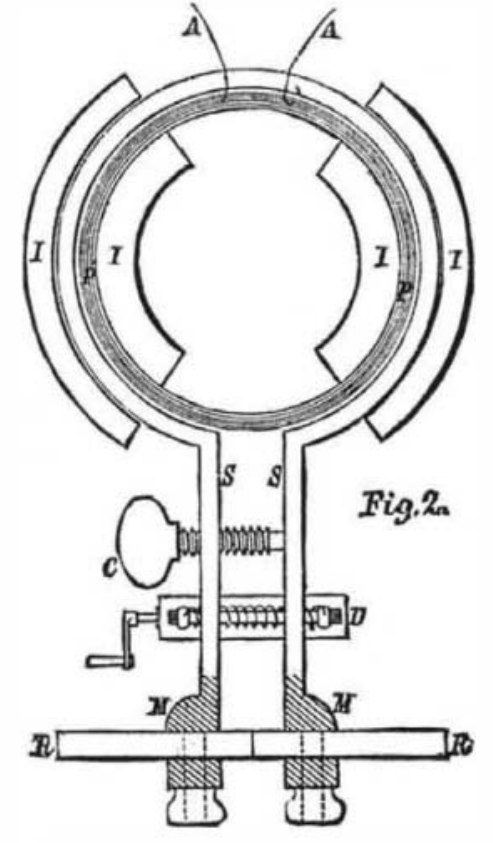

bita

and brass rods were similariy treated, and tests were perfectly sound.

SEPARATION OF NICKEL BY THE MAGNET. By Thomas T. P. Bruce Warren.

DuRING the winter of $1881-82$, while lecturing to a
class at the Silvertown Institution. on Electricity and class at the Silvertown Institution. on Electricity and Magnetism, I was desirous of showing to the students kindness of Matthew Gray, Esq., at that time President of the Institution, I borrowed from the India-rubber, Gutta-percha, and Telegraph Co., Silvertown, a specisamples received some time before from Germany. The difference in price of the two samples was so little that they were thrown together into a drawer, as it was
thought at the time that there could not be much difference between them with respect to purity, etc. A handful of these cubes was placed on the table,
and, on bringing an ordinary compound horse-shoe magnet near the cubes, I was very much surprised to find that, while some of these cubes were forcibly all, or so slightly that they could not be supported by the magnet against their own gravity. Some cubes
were attracted slightly. when placed very near to the were attracted slightly when placed very near to the
magnet, but could not be lifted.
I thought the matter of suffeient in terest that I
intrusted the chemical examination of these samples to one of the students in the laboratory of the Institution. tained in the drawer with the magnet in the same way, and in two or three minutes I had the samples sorted
out into their original lots of two kilogrammes each. out into their original lots of two kilogrammes each.
The magnet readily picked out the better quality at the rate of twenty or thirty cubes at a time, until what was left could not be drawn out by the magnet. To cubes were again tested with the magnet, when it was found that a few non-magnetic cubes had been drawn up by entanglement with the others. By the second There was no veiry marked difference in these cubes
which would lead one to suspect anything worth notwhich would lead one to suspect anything worth not-
ing. A closer examination showed that the non-magnetic cubes were a trifle whiter, and presented the though unequally, with the magnetic cubes. This method of examination was extended to samples of English grain nickel, and also to portions of anodes of English, American, and German manufacture.
It may be suffeient to remark here that the grain nickel was powerfully attracted, and that the anodes,
although drawn up by the magnet, were not so strongly The fact that nickel has become an article of comTercial importance, and that chemical analysis has disclosed the fact that this metal is liable to extensive adulteration, which can be so easily detected by the more extended examination

Special examinations of these cubes were made fo were decidedly absent, althoughr traces of some of were decidedly absent, although
these were detected in the anodes.

The following gives the percentage of composition of

\begin{tabular}{|c|c|c|}
\hline & Magnetic. & Non-mag \\
\hline Copp & 0.083 & $33 \cdot 779$ \\
\hline Carb & 0.071 & 0.365 \\
\hline Silica & $0 \cdot 409$ & $0 \cdot 160$ \\
\hline Iron $\ldots \ldots \ldots \ldots$ & $2 \cdot 457$ & 0.841 \\
\hline$\underset{T i n}{\text { Arsenic }} . \ldots \ldots \ldots \ldots \ldots \ldots \ldots \ldots$ & 0.117 & 0865 \\
\hline Tin & $\begin{array}{r}0.749 \\
96.670\end{array}$ & $\begin{array}{r}0.461 \\
63 \cdot 690\end{array}$ \\
\hline & & \\
\hline
\end{tabular}

The oxide of nickel obtained from the non-magnetic sample was reduced by heating in a current of hydro than the other sample. A portion was placed in a test ful horse-shas inserted between the poles of a power position, which was not disturbed on carefully rotating the tube.

Portions of this metal were alloyed with small quan-
tities of tin, arsenic, and antimony separately, which had a decided effect on its magnetic property.

whenalt in its pure state behaves like nickel, an affected. nickel crucibles and dishes, and also to the wire triangles both before and after heating. these crucibles, when strongly heated over a Bunsen burner, is very slight compared with the bulky accu-
mulation of black deposit which is produced. A few days ago I collected considerably over a gramme of with minute quantities of nickel, iron, and silica. I may mention that a platinum crucible heated in
the same flame remained quite bright. The curious deduction arising from this is that these vessels are capable of actually decomposing the gas in a Bunbe taken is not to use these supports for platinum cruThis unlooked for result led me to use hydrogen as a means of heating these nickel crucibles, taking care, of course, that the intense heat was not allowed to act injuriously on them. If coal gas be used,
the flame must not be allowed to impinge upon the crucible.

I have now some experiments in hand with a view of ascertaining their behavior in a muffle furnace, heated with ordinary gas, as alkaline fusions for the
analysis of earthy minerals are frequently required in practice.

practice. gains in weight, due to oxidation when heated in a muffle, but there is this difference-that the oxide
formed is strongly adherent to the crucible, and is not rubbed off by the fingers, in the hydrogen flame. Oxidation does not take place on heating, but the
precaution is necessary, to allow the cooling to go on in a current of this gas in order to avoid oxidation.

these rays only at the moment when the light acts upon the bodies, that is to say, according to the case,
either by means of the ultra violet light or, as the author has shown for the first time (see $A$ mances de Chimie et de Physique, 3d series, voi. iv., p. 9') by the aid of electric discharges or effluves in a vacuuni. In which have been named effects of fluorescence, and
which differ from others merely by their duration. Hence the effects presented by bodies excited by these different means are not the same. Further, in case of
the effluve the bodies may receive the influence of rays the effluve the bodies may receive the influence of rays
much more refrangible than those furnished by cenmuch more refrangible than those furnished by conby the electric dischar may be also directly excite vacuum excites bodies differently according to the degree of exhaustion, and one body may give no effect in an insufficient vacuum, while it is brilliant in one
more perfect. Conversely, another body may be more more perfect. Conversely, another body may be more are strongly excited in the phosphoroscope. It may differenty the efluve, acting upon mixtures, excites The effects observed in the phosphoroscope are more observed in a vacuum by means of the effluve are much the spectroscope we may deduce interesting conclusion the spectroscope we may deduce inter
as to the nature of the substances.

THE CAPILLARITY AND DENSITY OF LIQUIDS.

TAKE two glasses (claret glasses, for example), of exactly the same diameter at the rim, and immerse them in a pail of water. Before removing them from the
liquid, place them rim to rim, so that both shall re.

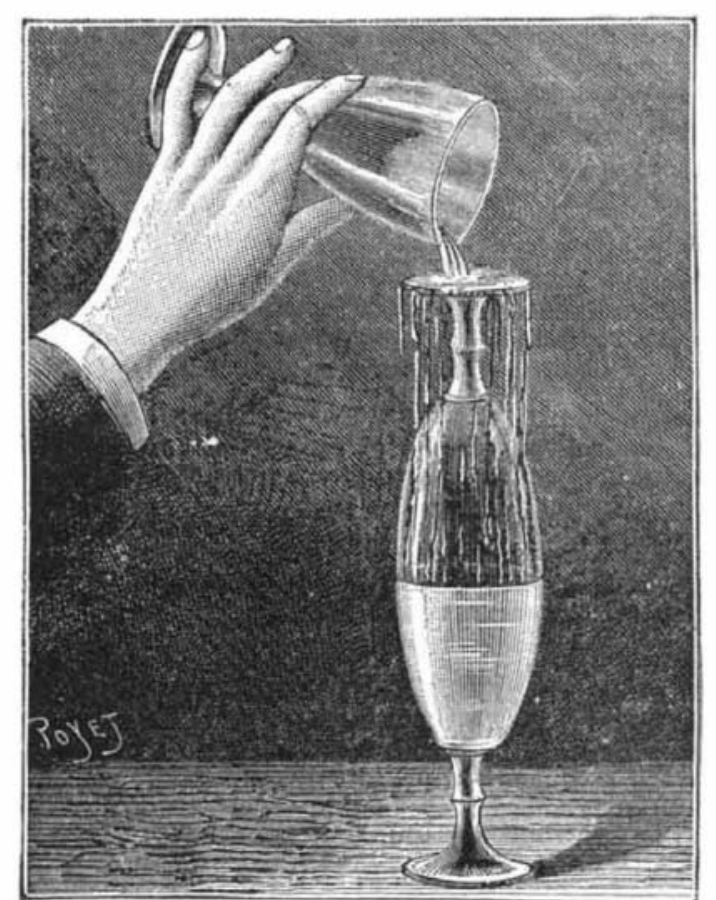

EXPERIMENT ON THE CAPILLARITY AND DENSITY OF LIQUIDS.

$I$ find that there is a difference in the composition of the nickel gauze and wire supports and the cru-
cibles and dishes. Malleability, so far as my analy-
ses go, is produced by the addition of iron and manses go, is produced by the addition of iron and man. The composition of the malleable alloy from which the dishes and crucibles ar

I may just state that commercial manganese and magnetic are met with, in which magnetic attraction is notoriously absent. This deserves attention, as in the construction of magnets other metals are added to iron to increase its retentive power when hardened,
and it is by no means improbable that the polarity of soft iron may be modified as regards its residual mag-
netism by the addition of other-metals of the same or opposite series.-Chem. News.

\section{PHOSPHORESCENCE OF ALUMINA.}

By EdMONd BECQUEREL. In a memoir recently presented by M. De Boisbaudran
to the Academy (vol. ciii., p. 1107), it is asserted that
very pure precipitated alumina, when excited by elecvery pure precipitated alumina, when excited by elec-
tric discharges in a vacuum, does not give a red light,
which, however, can be made to appear by the addiwhich, however, can be made to appear by the addi-
tion of $1-10,000$ oxide of chrome. The author of that memoir deduces from his observations that the characteristic red light is not derived from alumina, but is
due to the presence of chrome. $M$. Becquerel, on repeating the experiment with some of the very same material, obtained an opposite result, in conformity
with his former observations. Some fragments of this supposed pure alumina were îxed on a slip of mica
with a little gum, placed in the phosphoroscope, and excited by means of the electric arc. They gave an than the light emitted by alumina containing chromium oxide, and submitted to the same treat-
ment. But if this pure alumina is ignited for fifteen minutes in a porcelain crucible placed in a gas furnace fuminous and red in the phosphoroscope as alumina containing chrome. In the phosphoroscope we cansee tion, has a certain duration measured by the speed o rotation of the disks of the apparatus, but as aictiv bodies may emit, simultaneously, luminous rays the durations of which are different and shorter than that
measured by the rotation of the disks, we can perceiv main full of water, as shown in the figure. We shall thus have two glasses full of water and containing no
air. It will now be easy, by acting with caution, to separate them sightly, so as to leave a small space be-
tween their edges. Now take a third glass containin wine, and pour the latter, drop by drop, on the foot of the upper glass and allow it to spread over the latter's surface. Upon reaching the line of separation, the wine, instead of continuing its descent, will be seen to enter the water in the upper glass entirely red without tingeThe wine keeps to the upper glass through the acby reason of the difference in density of the two liquids.

This is an experiment that anybody can try, and one that may be utilized in a lecture course

We must add that the two glasses should be placed on a tray, or something of the kind, in order that the trickles down the lower glass, while but a fraction of it rises in the upper one.

\section{SULPHUROUS ACID IN THE CHEMICAL INDUSTRIES.}

THE process of extracting phosphate of lime from of sulphuric acid is known in chemistry by the publications of Gerland, of Pavesi and Rotondi, and others, 814 of 1879 . The crude phosphates are treated with a strong solution of sulphurous acid in water. The monobasic phosphate of lime, is heated, bibasic phosphate of hime is precipitated, and sulphurous acid is large quantities of free lime, or carbonate of lime, all
this lime is also dissolved by sulphurous acid as bisulwith the phosphate of lime, by heating the solution
obtained. This precipitate, therefore, would not contain more phosphoric acid than the crude phosphate By the process of Haenisch and Schroeder, Ger. pat phates is reduced to sulphate of lime by treating the crude phosphates with sufficient quantities of sul.
phuric acid. When treating phosphates prepared thus, the upper one, owing to the difference in density of
the wine and water. It is possible in this way to color vessels. If the crude phosphates contain, however,
vantion phite of lime, and will also be precipitated, togethe 